\title{
Cost Allocation in PPP Projects: An Analysis Based on the Theory of "Contracts as Reference Points"
}

\author{
Yichen Peng, ${ }^{1}$ Jing Zhou, ${ }^{1}$ Qiang $\mathrm{Xu},{ }^{1}$ and Xiaoling $\mathrm{Wu}{ }^{2}$ \\ ${ }^{1}$ School of Management and Engineering, Nanjing University, Nanjing 210000, China \\ ${ }^{2}$ School of Economics and Management, Nanjing University of Technology, Nanjing 210009, China \\ Correspondence should be addressed to Yichen Peng; pyc114@hotmail.com
}

Received 9 March 2014; Accepted 1 May 2014; Published 20 May 2014

Academic Editor: Xiaolin Xu

Copyright (c) 2014 Yichen Peng et al. This is an open access article distributed under the Creative Commons Attribution License, which permits unrestricted use, distribution, and reproduction in any medium, provided the original work is properly cited.

\begin{abstract}
In recent years, the demand for infrastructure has been largely driven by the economic development of many countries. PPP has proved to be an efficient way to draw private capital into public utility construction, where ownership allocation becomes one of the most important clauses to both the government and the private investor. In this paper, we establish mathematical models to analyze the equity allocation problem of PPP projects through a comparison of the models with and without the effects of the theory of "contracts as reference points." We then derive some important conclusions from the optimal solution of the investment ratio.
\end{abstract}

\section{Introduction}

In recent years, the demand for infrastructure has been largely driven by the economic development of many countries. Hence governments, especially those of developing countries, face great pressure to find new ways to meet the financial needs of an increasing number of infrastructure projects. PPP (public-private-partnership) is a collaboration through which the public and private sectors both bring their complementary skills into an infrastructure project and receive different levels of benefit based on their proportion of investment and responsibility [1]. PPP has proved to be an efficient way to draw private capital into public utility construction as it not only solves financial problems by utilizing private capital to oversee the designing, financing, building, and operation of the project, but also enhances the level and the efficiency of management [2].

Under PPP mode, how to allocate the asset ownership becomes one of the most important clauses to both the government and the private investor. Usually, the allocation of profit depends on two factors. First, like other cooperation partnerships, the government and the private sector gain earnings in proportion to their investment scales. In addition, the level of risks that each sector undertakes also determines the profit that each can obtain. There are many papers which discuss how to allocate different risk factors between the two parts, many of which suggest that the risks each sector is responsible for should be written in the contract. Once a risk occurs, the government and the private sector can investigate and affix the responsibility for it according to the contract. In the early stages of research, scholars did not think that the issue of risk allocation should follow a common rule. Furthermore, some scholars insisted that one of the key aspects of PPP is that the private sector should assist the government in accomplishing the infrastructure program [3]. However, in the practical application of PPP mode, many cases show that risk allocation should follow some principles. In summary, the cost, the risk, and the profit are three main provisions that should be made in the contract. In fact, risk allocation has become one of the most important issues in current research and many scholars have put forward different views on it. Rutgers and Haley believe that the risks should be assigned to the sector that can control it well [4]. On the other hand, Crampes and Estache analyzed the influence of risk preference to risk allocation. When both the government and the private enterprise were risk neutral, there was no necessity to discuss the issue. However, if the private sector was risk averse, and the government was risk neutral, most of the risks should be allocated to the public sector [5]. Bing et al. explored preferences in risk allocation. 
Their paper shows that some macro- and microlevel risks should be retained within the public sector or shared with the private sector. The majority of risks in $\mathrm{PPP} / \mathrm{PFI}$ projects, especially those in the mesolevel risk group, should be allocated to the private sector [6]. Xu et al. developed a fuzzy synthetic evaluation model for determining equitable risk allocation between the government and the private sector, which assists PPP project practitioners in transforming the risk allocation principles from linguistic terms to a more usable and systematic quantitative-based analysis through the fuzzy set [7]. Medda believes that the process of risk allocation between the two sectors is a bargaining process, and the process could be modeled with a final offer arbitration game. Her paper shows that when guarantees have a higher value than financial loss, we are confronted with strategic behavior and potential moral hazard problems [8]. Ke et al. conducted a two-round Delphi survey to identify the preference of risk allocation in China's PPP projects. They concluded that the government should take the majority of responsibility for thirteen of the risks, whereas the private sector should take responsibility for ten of them, with the rest shared between the two parts [9]. To sum up, there are two principles that are generally accepted: the risk should be assigned to the sector that can control it efficiently, and authority, responsibility, and profit must match.

Equity allocation is an issue that western scholars have paid little attention to and which only a handful of Chinese researchers have conducted studies on. Besley and Ghatak analyzed how ownership matters in public good provision and showed that the party that can better value the benefits generated by the project should own it [10]. Chinese scholars Zhang et al. believed that PPP is a cooperation based on contracts, so control rights become the key influence factor in determining the efficiency of PPP projects. On the basis of this idea, a new analysis frame was proposed [11]. In a subsequent paper, Zhang et al. again pointed out that the key factor of PPP cooperation efficiency is the allocation of control rights from the perspective of incomplete contracts and established mathematical model to analyze the relationship between the allocation of control rights and the cooperation efficiency in the context of PPP projects. This paper showed that the key to enhance PPP efficiency is allocating different degrees of control rights to the public sector or the private one based on different parameters [12]. Ye et al. discussed the essence of control rights in PPP projects and insisted that control rights constitute not only a form of choice for the cooperation between public and private, but also a condition of obligation for both parties [13]. Further, they presented an interest distribution model based on risk adjustment. The model takes both the investment scale and risk allocation into account to allocate the profits fairly and proportionately. However, in this paper the authors only proposed the expressions of the profit of the two parties. The optimal allocation proportion was not calculated [14]. $\mathrm{Hu}$ et al. also established a benefit allocation model using the value method of SHAPELY to maximize the participants' profit and showed through numerical analysis how optimality can be obtained under this model [15]. In summary, by reviewing previous literatures, we can find that many studies have discussed the risk and cost allocation of PPP project. Some of them realized that both of the two factors played an important role in equity allocation, but none of them deduced the optimal cost allocation proportion.

One of the key defining features of PPP is the contractual cooperation of the government and the private enterprise to maximize the benefits they expect to get, while sharing both complementary advantages and risk. From this perspective, we can consider the PPP participants as constituting a form of strategy alliance, which is a topic that most papers analyze through game theory. Initially, scholars only took two players into account, before expanding it to include three or more players $[16,17]$. However, all of these papers established the game model based on the hypothesis of personal rationality. In recent years, many psychology experiments have shown that people would be influenced by their mental perception, including the need for fairness and their dependence on reference points $[18,19]$. In 2006, Hart and Moore proposed a new method of analyzing the processes of decision-making in trading by using contracts as reference points, which takes into consideration the parties' feelings of entitlement. A participant's ex post performance depends on whether he earns what he is entitled to as permitted by the contract. If he is shortchanged, he will shade on performance [20]. Gao and $\mathrm{Xu}$ applied this theory to analyze the utility of the alliance's members under four different situations [21]. Similarly, it is necessary to consider the feelings of entitlement of PPP participants.

To enhance the current models, based on the mathematic descriptions of risk and cost in previous literatures, we analyze the equity allocation problem of PPP projects by comparing the results with and without the effect of the theory of "contracts as reference point." We assume that the risks are assigned to the sector that can control it efficiently through the negotiation, and to maximize the total surplus, we derive the optimal cost allocation proportion. The finding shows that the satisfaction of the equity allocation will influence the utility of the participants of PPP projects. The less the satisfaction, the less the cost the participants will pay. In the following parts of the paper, we first set up the basic model and give some assumptions. Then we calculate the optimal investment scale when the theory of "contracts as reference points" is not considered. Subsequently, we take the theory into consideration to solve the optimal proportion. Finally, we derive some important conclusions based on the two results.

\section{Basic Model and Some Assumptions}

We assume that the government plans to build an infrastructure under PPP mode. The project is jointly funded by the government and the private sector. Thus the proportion of the profit distribution is supposed to be decided by the investment scale and risk taking scale. Here we assume that the investment ratio of the government is $k(0<k<1)$ and the risk ration that the government takes is $\omega_{g}$, while the relevant ratios for the private sector are $1-k$ and $\omega_{s}$. $\lambda(0<\lambda<1)$ reflects the importance of investment in profit 
allocation, and $1-\lambda$ is the importance of risk taking. The profit of the project is $R$. The private sector has an opportunity utility, which refers to the utility that the private enterprise could get when he does not join the program. Thus, if the government wants to draw the private sector to invest in the project, the public sector should assure the private sector of getting the opportunity profit from the project. Here we assume that the opportunity profit is $\bar{R}$. So the basic object programming model is

$$
V=\left[\operatorname{Max} f_{1}(k), \operatorname{Max} f_{2}(k)\right],
$$

where $f_{1}(k)$ refers to the profit function of government,

$$
f_{1}(k)=R\left[\lambda k+(1-\lambda) \omega_{g}\right]
$$

and $f_{2}(k)$ refers to the profit function of the private sector

$$
f_{2}(k)=R\left[\lambda(1-k)+(1-\lambda) \omega_{s}\right] .
$$

In the following parts, we will compare the models with and without the effect of the theory of "contracts as reference points." First, we analyze the simple model without the contract reference point dependence.

\section{The Equity Allocation Model without "Contracts as Reference Point" Theory}

In this situation, $f_{2}(k) \geq \bar{R}$, that is, $f_{2}(k)=R[\lambda(1-k)+(1-$ $\left.\lambda) \omega_{s}\right] \geq \bar{R}$. We assume that the public sector here is the agent of the social commonage. So the government should not pursue the economic profit. The profit that the government want to earn is $f_{1}(k) \geq 0$, that is, $f_{1}(k)=R\left[\lambda k+(1-\lambda) \omega_{g}\right] \geq 0$.

Here we take the total surplus as the objective function, and the utility function is additive, that is, $F(k)=\sum_{j=1}^{2} f_{j}(k)$. So the objective function is

$$
F(k)=\operatorname{Max} \sum_{j=1}^{2} f_{j}(k) .
$$

And the constraint conditions are

$$
\begin{gathered}
R\left[\lambda(1-k)+(1-\lambda) \omega_{s}\right] \geq \bar{R}, \\
R\left[\lambda k+(1-\lambda) \omega_{g}\right] \geq 0 .
\end{gathered}
$$

By applying the Lagrange function, we can solve the singleobjective programming problem. Its Lagrange function is

$$
L\left(k, \lambda_{1}, \lambda_{2}\right)=f_{1}(k)+f_{2}(k)+\lambda_{1} f_{1}(k)+\lambda_{2}\left[f_{2}(k)-\bar{R}\right] .
$$

So it can be expressed as

$$
\begin{aligned}
L\left(k, \lambda_{1}, \lambda_{2}\right)= & \left\{R\left[\lambda k+(1-\lambda) \omega_{g}\right]\right\} \\
& +\left\{R\left[\lambda(1-k)+(1-\lambda) \omega_{s}\right]\right\} \\
& +\lambda_{1}\left\{R\left[\lambda k+(1-\lambda) \omega_{g}\right]\right\} \\
& +\lambda_{2}\left\{R\left[\lambda(1-k)+(1-\lambda) \omega_{s}\right]-\bar{R}\right\} .
\end{aligned}
$$

The first order conditions are

$$
\begin{gathered}
\frac{\partial L}{\partial k}=\lambda_{1}-\lambda_{2}=0, \\
\frac{\partial L}{\partial \lambda_{1}}=R\left[\lambda k+(1-\lambda) \omega_{g}\right]=0, \\
\frac{\partial 0}{\partial \lambda_{2}}=R\left[\lambda(1-k)+(1-\lambda) \omega_{s}\right]-\bar{R}=0 .
\end{gathered}
$$

Thus, the optimal solution of $k$ is

$$
k=1-\frac{\bar{R}-R(1-\lambda) \omega_{s}}{R \lambda} .
$$

From this solution, we can draw some important conclusions.

(1) $(\partial k / \partial R)=\left(\bar{R} / R^{2} \lambda\right)>0$, which means that the government will invest more with the growth of the expected profit of the PPP project. Although we assume that the government does not pursue economic benefits, if the profit is more than expected, the government would get more equity to get more control rights and guarantee a proper social benefit of the infrastructure program to avoid the private sector from earning too much profit.

(2) $\left(\partial k / \partial \omega_{s}\right)=((1-\lambda) / \lambda)>0$. From this characteristic, we can see that the higher the risk the private company takes, the more the cost which the government pays. Generally speaking, the purpose of the government in launching the program is to bring social benefit to the public. So the government may prefer to take less risk in the program to guarantee social profit. If the private sector is willing to take more risk, the government should be ready to cut down its equity to make up for the private sector's venture cost.

(3) $(\partial k / \partial \lambda)=\left(\left(\bar{R}-\omega_{s} R\right) / R \lambda^{2}\right)$, when $\omega_{s}<(\bar{R} / R)$, $(\partial k / \partial \lambda)>0$; when $\omega_{s}>(\bar{R} / R),(\partial k / \partial \lambda)<0$. This means that when the risk ratio that the private enterprise takes is in a certain range, with the growth of the importance of investment, the government is willing to pay more cost. On the contrary, when the risk ratio that the private enterprise takes exceeds a certain value, with the growth of the importance of investment, the government will not be willing to pay much in the program. The reason for this is the government has to invest more to get the profit control right if the private company is not willing to take much risk, so that the government could balance its profit and loss.

In conclusion, if the risk sharing ratio is constant, with the growth of the expected profit of the PPP project, the government will invest more in it. When the risk of the program is low, the government will be willing to pay more cost. When the program faces high risk, the government is inclined to transfer the risk to the private company who can control it. Thus a risk-averse government can choose the investment ratio dynamically to defend the high risk. 


\section{The Equity Allocation Model with "Contracts as Reference Point" Theory}

According to Hart's theory, a trade is partially contractible. Correspondingly, the joint utility is divided into two parts. The first part is called perfunctory performance, which is within the letter of the contract and can be observed. So this part of the utility is judicially enforced because of the contract. The second part is consummate performance. This kind of utility cannot be observed because this performance is within the spirit of the contract, so it cannot be enforced by the contract ex ante. Hart insists that one party of the trade will be willing to provide all the consummate performance if he feels that he is getting what he is entitled to. The entitlement is measured relative to the contract. But when he feels shortchanged, he will withhold some part of the consummate performance, that is, the degree of satisfaction of each party decided by the contract, which is the reference point that is considered in this paper. Gao and $\mathrm{Xu}$ applied Hart's theory in analyzing the utility function of strategy alliance member. In their paper, when the members in a strategy alliance distribute the profit, their incomes include perfunctory performance and consummate performance. They gave a simple example in their work. Here are two members in the alliance. $u_{i}(i=1,2)$ represents the perfunctory performance (common benefit), which are written in the contract. $\alpha_{i}(i=1,2)$ represents the difference between reference point and common benefits, whereas $\sigma_{i}(i=1,2)$ refers to the opportunist benefit. The opportunist benefit only occurs when a party's speculation behavior encroaches on the other's benefit. $\theta$ denotes that one dollar of $\alpha$ brings $\theta$ dollars loss in spirit, that is, for each dollar that a party feels shortchanged by, he shades his performance so that the other party's payoff falls by $\theta$ dollars, where $0 \leqslant \theta \leqslant 1$. Here we assume that $\theta_{1}=\theta_{2}=\theta$. The utility functions of alliance members are

$$
\begin{aligned}
& U_{1}=u_{1}-\sigma_{2}-\max \left\{\theta \alpha_{1}-\sigma_{1}, 0\right\}, \\
& U_{2}=u_{2}-\sigma_{1}-\max \left\{\theta \alpha_{2}-\sigma_{2}, 0\right\} .
\end{aligned}
$$

Based on this model, the utility of a member is equal to the common benefit defined by the contract, minus the probable opportunist profit encroached on by the other member, and minus the difference between the opportunist profit encroached on from the other member and the benefit he thinks he should get in addition to the common profit. Here we want to emphasize that when both of the two members' $\alpha$ is equal to zero or not, the total utility of this alliance is equal to the total profit minus the sum of $\alpha_{i}(i=1,2)$. To simplify the analysis, we ignore the opportunist benefit, that is,

$$
\begin{aligned}
& U_{1}=u_{1}-\theta \alpha_{1}, \\
& U_{2}=u_{2}-\theta \alpha_{2} .
\end{aligned}
$$

In Hart's paper, he took $\theta$ to be exogenous and constant. However, we think that $\theta$ should be endogenous and variable. To set up our model, we give some assumptions.
Assumption 1. Both of the government and the private sector's opportunist benefits are equal to zero.

Assumption 2. $\theta$ is relevant to the investment amount. So it is different between the government and the private sector.

Assumption 3. For the government, $\theta_{g}=\beta k^{2}$. Here $\partial \theta_{g} / \partial k>$ $0, \partial^{2} \theta_{g} / \partial k^{2}>0$ means that the more the government pays, the more the loss is, when it thinks the profit allocation is unfair, and the faster the loss increases. Similarly, for the private sector, $\theta_{s}=\beta(1-k)^{2}$.

On basis of above assumptions, the objective function is

$$
\begin{aligned}
\max & \left\{R\left[\lambda k+(1-\lambda) \omega_{g}\right]-\theta_{g} \alpha_{1}\right\} \\
& +\left\{R\left[\lambda(1-k)+(1-\lambda) \omega_{s}\right]-\theta_{s} \alpha_{2}\right\} .
\end{aligned}
$$

To maintain the alliance, the constraint conditions are

$$
\begin{gathered}
R\left[\lambda k+(1-\lambda) \omega_{g}\right]-\theta_{g} \alpha_{1} \geq 0, \\
R\left[\lambda(1-k)+(1-\lambda) \omega_{s}\right]-\theta_{s} \alpha_{2} \geq \bar{R} .
\end{gathered}
$$

To solve the problem, we calculate its $K-T$ conditions by bringing in the Lagrange multipliers $\mu_{1}$ and $\mu_{2}$

$$
\begin{aligned}
& 2 \beta \alpha_{1} k-2 \beta \alpha_{2}(1-k)+\mu_{1}\left(2 \beta k \alpha_{1}-R \lambda\right) \\
& +\mu_{2}\left[-2 \beta \alpha_{2}(1-k)+R \lambda\right]=0, \\
& \mu_{1}\left\{R\left[\lambda k+(1-\lambda) \omega_{g}\right]-\theta_{g} \alpha_{1}\right\}=0, \\
& \mu_{2}\left\{\bar{R}-R\left[\lambda(1-k)+(1-\lambda) \omega_{s}\right]-\theta_{s} \alpha_{1}\right\}=0, \\
& \mu_{1}, \mu_{2} \geq 0 .
\end{aligned}
$$

From the above equation set, we can get the optimal investment scale.

Proposition. Under the assumption of "contracts as reference point" theory, the optimal investment scale of the government in the PPP project is

$$
k=\frac{\alpha_{2}}{\alpha_{1}+\alpha_{2}}, \quad\left(\alpha_{1}, \alpha_{2}>0\right) .
$$

Accordingly, the optimal scale for the private sector is

$$
1-k=\frac{\alpha_{1}}{\alpha_{1}+\alpha_{2}}
$$

where $\alpha_{i}(i=1,2)$ represents the difference between the reference point and common benefits. And the risk that the government takes satisfies

$$
\omega_{g} \in[0, h] .
$$

Here

$$
h=\frac{\bar{R}\left(\alpha_{1}+\alpha_{2}\right)^{2}+\beta \alpha_{2} \alpha_{1}^{2}-R \lambda \alpha_{1}^{2}-R \lambda \alpha_{1} \alpha_{2}}{R(1-\lambda)\left(\alpha_{1}+\alpha_{2}\right)^{2}}
$$

From the proposition, we draw some conclusions. 
(1) When taking Hart's theory into consideration, the optimal investment ratio is only relevant to the parameters $\alpha_{i}(i=1,2)$, that is, the satisfaction degree to the result of ownership allocation. In this paper, we take the total utility as the objective function. This result illustrates that, in cases where self-interest is guaranteed, the satisfaction degree of the participants in the PPP project decides whether the total utility of the system can reach the maximum value. One's optimal investment proportion is the ratio of the other's difference between the reference point and common benefits in the sum of the participants' difference between the reference point and common benefits. $\left(\partial k / \partial \alpha_{1}\right)<0$ means that if the government is discontent with the allocation result, it will invest less cost in the project. The same explanation is also suitable for the private sector.

(2) From expressions (17) and (18), we can see that when the risk that the government takes is below a certain value, the alliance can be maintained and the negotiation between the two parties could be successful. Comparing with the result of part 3 , the parties' utilities of the project are decided not only by the economic benefits, but also by the satisfaction degree of the ownership allocation result. Thus, to avoid discontentment, the parties will adjust not only the cost they pay but also the risk they take, to make up for the psychological loss they may suffer. Since the government cares for the social benefit more, the risk that the public sector is willing to take has a limit. If the government takes too much risk, the social benefit of the project will suffer a loss. However, the economic benefit for the private sector should be guaranteed, so the risk that the private sector takes should be beyond a certain ratio.

(3) $(\partial h / \partial R)<0$ means that the higher the profit that the project earns, the less the risk that the government is happy to take. This is because when the profit is beyond expectations, the discontent degree may increase. So the motivation of investing declines. $(\partial h / \partial \bar{R})>0$ illustrates that the higher the opportunity benefit of the private sector is, the higher the risk the government may take. This is because the willingness of investment will increase if the private sector has more desire to obtain ownership of the project. So the range of risk that the government takes will be wider.

\section{Conclusion}

In this paper, we establish mathematic models to analyze the equity allocation problem of PPP projects, by comparing the models with and without the effect of the theory of "contracts as reference point." Subsequently, we derive some important conclusions from the optimal solution of the investment ratio.

Without the assumption of reference point dependence, the optimal allocation of the participants' investment proportions is decided by the risk they take, the profit of the project, the expectation profit, and the importance of investment. If the government is risk averse, the optimal contract should be flexible, so that the government can choose the investment ratio dynamically to defend the high risk.

On the contrary, if we take the reference point into consideration, the satisfaction degree of the participants in the PPP project decides whether the total utility of the system can reach the maximum value. The less the satisfaction is, the less the cost the participants will pay. Besides, the risk that the parties are willing to share is affected by many factors. The parties' utilities of the project are decided not only by the economic benefits, but also by the satisfaction degree of the ownership allocation result. Thus, to avoid discontentment, the parties will adjust not only the cost they pay but also the risk they take, to make up for the psychological loss they may suffer.

In summary, the satisfaction of the equity allocation will influence the utility of the participants of PPP projects. Thus, it is necessary to take the mental factor into consideration in decision-making processes. In this paper, we take the total surplus as the objective function. However, the decision process may be more complicated. Usually, both of the public and the private sectors are inclined to maximize their own utility when they make decision. Thus, the game model may be more appropriate to describe their decision process. In our future work, we will pay more attention to the game problem between the participants to make our study even more practical.

\section{Conflict of Interests}

The authors declare that there is no conflict of interests regarding the publication of this paper.

\section{Acknowledgments}

The authors would like to thank the anonymous referees and the editor for the comments. The research was supported by the National Nature Science Foundation (70831002), China Postdoctoral Science Foundation (2012M521053), and Philosophy and Social Science Fund of Jiangsu Province Education Office (2012SJB630029).

\section{References}

[1] A. P. C. Chan, P. T. I. Lam, D. W. M. Chan, E. Cheung, and Y. Ke, "Critical success factors for PPPs in infrastructure developments: Chinese perspective," Journal of Construction Engineering and Management, vol. 136, no. 5, pp. 484-494, 2010.

[2] Y. Peng, J. Zhou, and X. Wu, "Concession period of BOT project analysis with dependence on reference point," in Proceedings of the Industrial Engineering and Management Science Conference, Shanghai, China, 2013.

[3] D. Dai and J. Song, BOT Projects Concession Decision Management, Publishing House of Electronics Industry, Shanghai, China, 2010, Chinese.

[4] J. A. Rutgers and H. D. Haley, "Project risks and risk allocation," Cost Engineering, vol. 38, no. 9, pp. 27-30, 1996. 
[5] C. Crampes and A. Estache, "Regulatory trade-offs in the design of concession contracts," Utilities Policy, vol. 7, no. 1, pp. 1-13, 1998.

[6] L. Bing, A. Akintoye, P. J. Edwards, and C. Hardcastle, "The allocation of risk in PPP/PFI construction projects in the UK," International Journal of Project Management, vol. 23, no. 1, pp. 25-35, 2005.

[7] Y. Xu, A. P. C. Chan, and J. F. Y. Yeung, "Developing a fuzzy risk allocation model for PPP projects in China," Journal of Construction Engineering and Management, vol. 136, no. 8, pp. 894-903, 2010.

[8] F. Medda, "A game theory approach for the allocation of risks in transport public private partnerships," International Journal of Project Management, vol. 25, no. 3, pp. 213-218, 2007.

[9] Y. Ke, S. Wang, A. P. C. Chan, and P. T. I. Lam, "Preferred risk allocation in China's public-private partnership (PPP) projects," International Journal of Project Management, vol. 28, no. 5, pp. 482-492, 2010.

[10] T. Besley and M. Ghatak, "Government versus private ownership of public goods," Quarterly Journal of Economics, vol. 116, no. 4, pp. 1343-1372, 2001.

[11] Z. Zhang, M. Jia, and D. Wan, "The optimal control rights allocation of PPP projects in perspective of incomplete contracts and relational contract," Foreign Economics \& Management, vol. 29, no. 8, 2007.

[12] Z. Zhang, M. Jia, and D. Wan, "Theoretical study on the efficient allocation of control rights in the public-private partnership (PPP)," Journal of Industrial Engineering/Engineering Management, vol. 23, no. 3, pp. 23-30, 2009.

[13] X. Ye, P. Yi, and S. Wu, "The discussion of PPP project control rights' essence," Science \& Technology Progress and Policy, vol. 28, no. 13, 2011.

[14] X. Ye, S. Wu, and X. Shan, "Research on interests relationship and distribution mode of PPP programe in China," Science \& Technology Progress and Policy, vol. 27, no. 19, pp. 36-39, 2010.

[15] L. Hu, W. Zhang, and X. Ye, "Profit allocation of PPP model based on the revised SHAPELY," Journal of Industrial Engineering/Engineering Management, vol. 25, no. 2, pp. 149-154, 2011.

[16] S. H. Park and D. Zhou, "Firm heterogeneity and competitive dynamics in alliance formation," Academy of Management Review, vol. 30, no. 3, pp. 531-554, 2005.

[17] M. Zeng and X.-P. Chen, "Achieving cooperation in multiparty alliances: a social dilemma approach to partnership management," Academy of Management Review, vol. 28, no. 4, pp. 587605, 2003.

[18] E. Fehr and K. M. Schmidt, "A theory of fairness, competition, and cooperation," The Quarterly Journal of Economics, vol. 114, no. 3, pp. 817-868, 1999.

[19] D. T. Kahneman, "A prospect theory: an analysis of decision under risk," Econometrica, vol. 47, no. 2, pp. 263-291, 1979.

[20] O. Hart and J. Moore, "Contracts as reference points," Quarterly Journal of Economics, vol. 123, no. 1, pp. 1-48, 2008.

[21] G. Gao and F. Xu, "Decision making on the benefits of strategic alliance reference points analysis based on contracts," Journal of Systems \& Management, vol. 20, no. 3, pp. 335-339, 2011. 


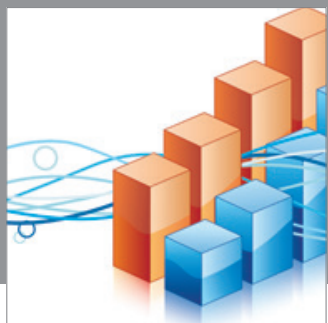

Advances in

Operations Research

mansans

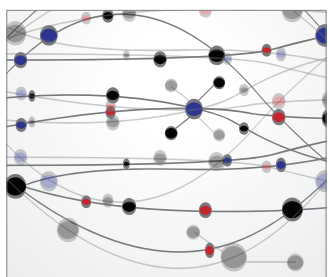

The Scientific World Journal
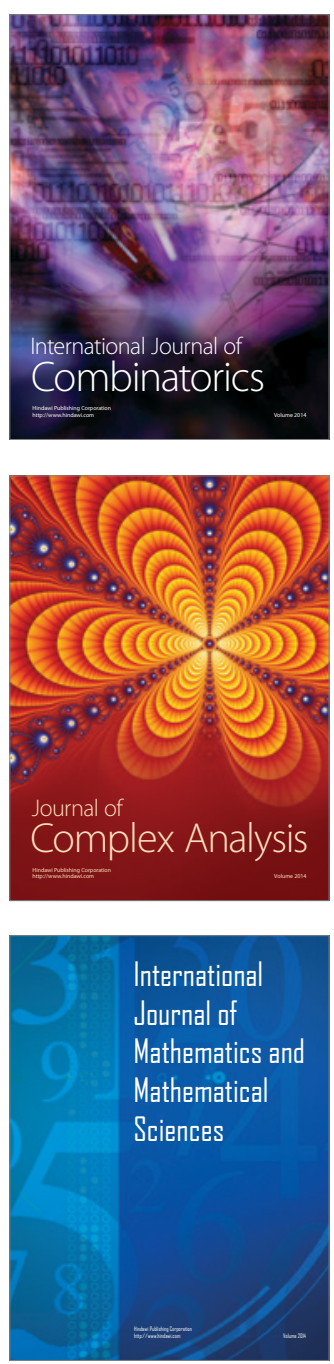
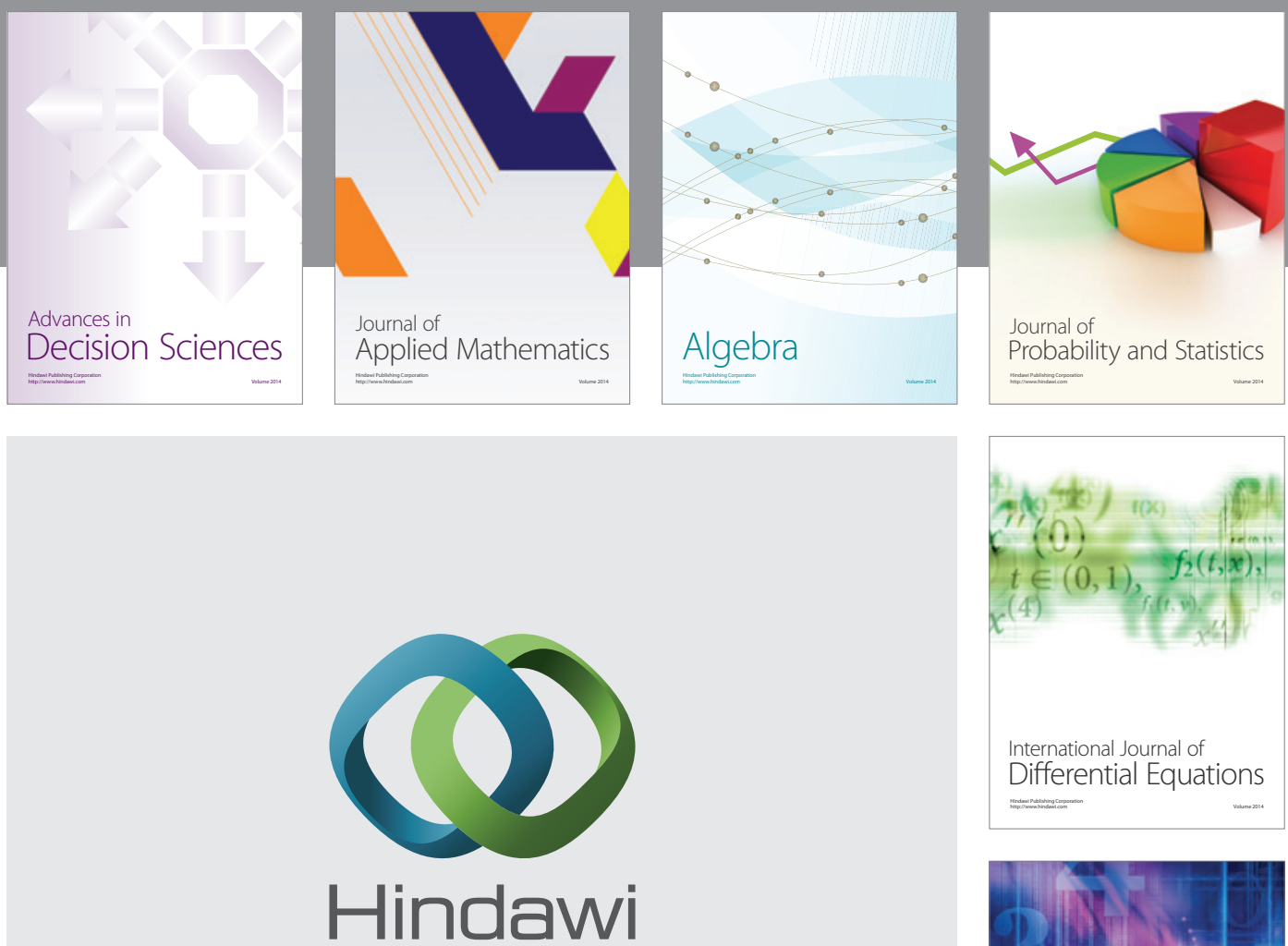

Submit your manuscripts at http://www.hindawi.com
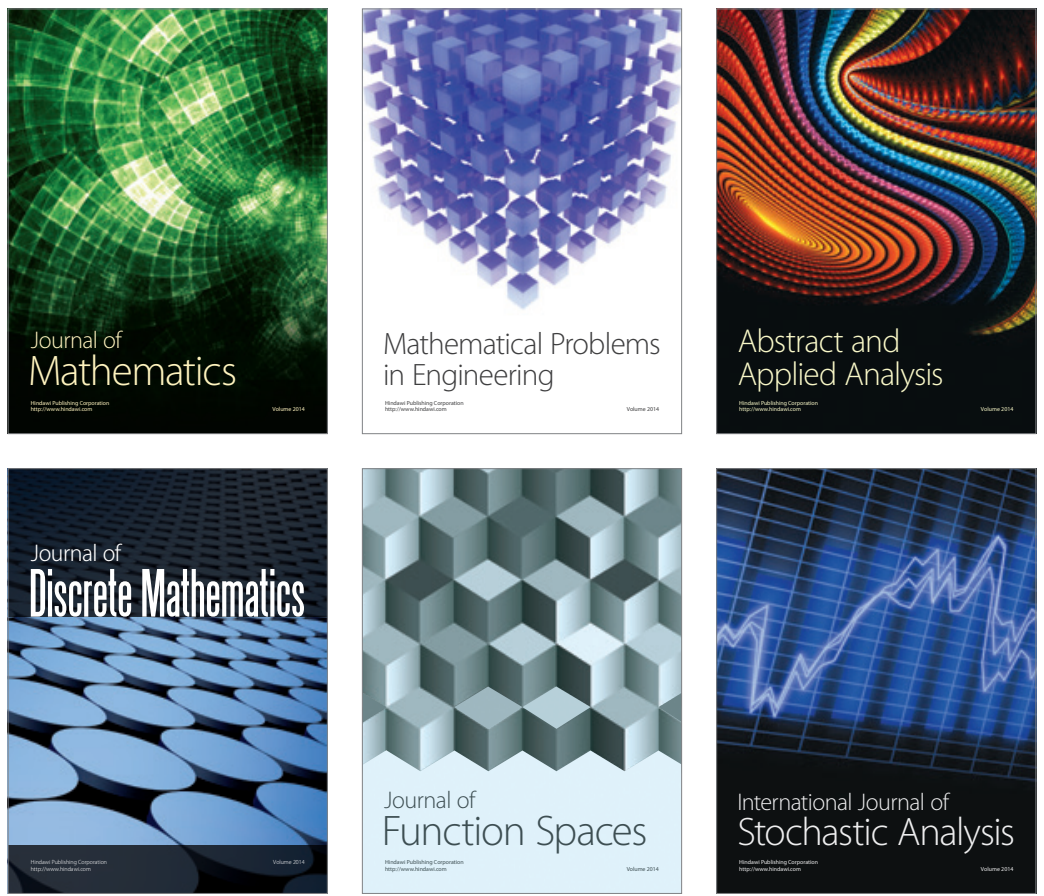

Journal of

Function Spaces

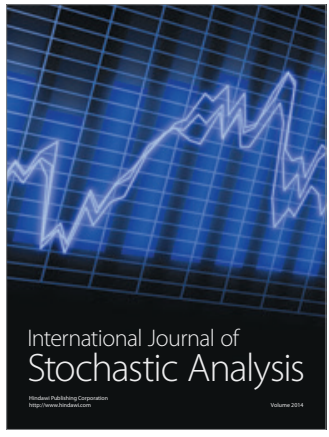

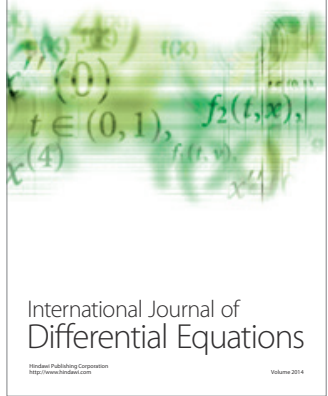
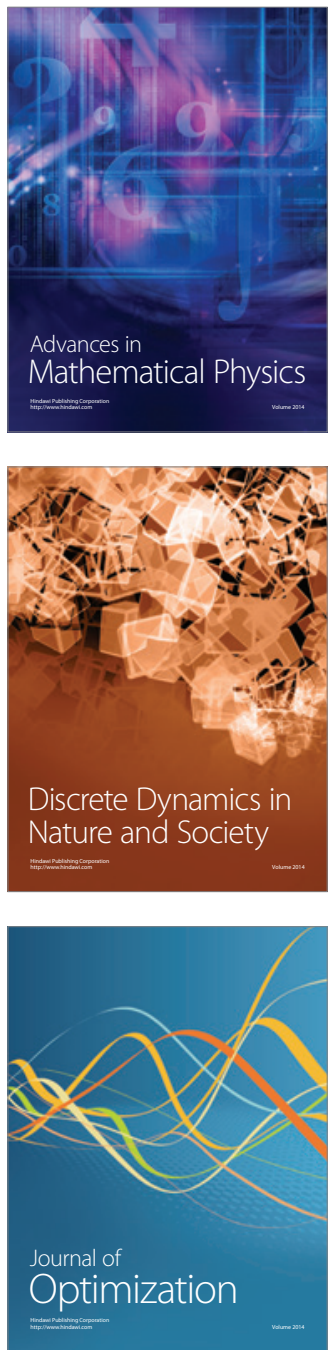